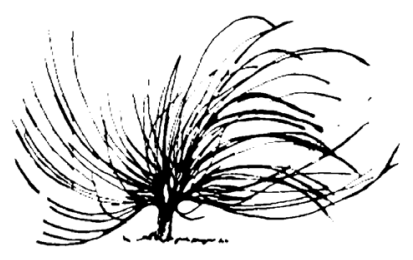

\title{
Freire y la Pedagogía del Oprimido
}

Óscar Rivas Mongel

Universidad Nacional

Costa Rica

oscar0890@hotmail.es

"La historia de la humanidad empezó con un acto de desobediencia y es muy probable que termine con un acto de obediencia".

Eric Fromm (1984, p. 41)

\section{El problema: ¿Educación o adoctrinamiento?}

La educación juega un papel fundamental en la composición del mundo, es por medio de esta que la especie evoluciona y el conocimiento pasa de generación en generación durante la historia. Sin embargo, esa condición antropológica es aprovechada por las clases dominantes para perpetuar su condición de poder, lo cual nos lleva a hablar concretamente de tipos de educación, o bien -para el rescate de su concepto-, de educación o adoctrinamiento.

La situación sistémica actual vuelve imperativo interpelarnos sobre el problema educativo. La burguesía, a través de los procesos educativos y su incidencia en la dinámica social, pretende ideologizar -a pesar de las contradicciones de la civilización capitalista- con más fuerza en la cotidianidad -dentro y fuera de las aulas-, a pesar de su incapacidad coyuntural, de un sistema agotado, de garantizar la satisfacción procesual de las necesidades básicas de la humanidad.

Se pretende un estrangulamiento: se trata de lograr que la educación deje todos los resabios críticos que aún le quedan y se dirija totalmente a crear sujetos pasivos, funcionales a operaciones ultra específicas de las cuales saca rédito el capital. Se tiene a la vista la ultra tecnificación de la enseñanza desde el ámbito académico hasta el existencial.

1 Bachiller en la Enseñanza de la Filosofía, UNA 
Existe una necesidad de poner todo en entredicho. La crisis sistémica lleva, por medio de sus contradicciones, a una crisis de humanidad, este período histórico encuentra urgencia de llegar a la raíz de los actos, se trata de dilucidar qué concepción de mundo y de ser humano se encubren no solo en los actos opresores, sino también en las luchas que diariamente se dan.

La educación no se encuentra exenta de estos problemas; esta, y su componente pedagógico, necesitan de una indagación, una búsqueda de sus motivos y de su génesis; preguntar por -y visibilizar- los elementos epistemológicos, políticos y éticos, para esclarecer los intereses que se esconden detrás de cada planteamiento educativo, y además velar por la mejor práctica pedagógica, con la finalidad de que los que realmente sufren -los oprimidos- puedan salir de la precarización en la que se encuentra su pensar, su sentir y su ser, en razón de la misma lógica sistémica, que los condena a perderse como seres humanos y a ser concebidos como objetos de la realización de la ganancia.

Ante esto, es necesario recuperar los planteamientos y concepciones que apuestan por una visión alternativa -no legitimante de la hegemonía- de lo pedagógico, por la recuperación del sujeto en la trasformación de su cotidianidad y de la totalidad sistémica, planteamientos que devienen del marxismo como los de la escuela Frankfurt (Adorno y Horkheimer, 2006) con su apuesta por la teoría crítica o por el planteamiento de una pedagogía del oprimido, como lo hace Freire (1970), recogiendo también los aportes de Fromm (1967) y de todos aquellos que ven en la forma educativa actual y en el vivir diario sin reflexión, uno de los principales factores que niegan la emancipación del ser humano, su humanización.

El presente trabajo analiza el pensamiento de Freire sobre la pedagogía, su constante lucha por encontrar una que sea dialogante con el oprimido, su idea de la relación entre educador y educando, y la apuesta por la transformación del mundo como única forma de llegar al homo sapiens hominis, a la desalienación.

\section{El marxismo como propuesta humanista en la educación}

El planteamiento de Freire es una respuesta a dos concepciones de mundo que aún hoy permanecen en cualquier postura sobre la realidad, discute tanto con el positivismo eurocéntrico como con el materialismo 
objetivista de corte estalinista-soviético, ambos culpables de borrar el sujeto de la historia y plantear el mecanicismo -fiel a la herencia newtoniana- como forma reductible en la que se mueve la realidad.

Freire recupera el planteamiento de Marx, que supera la concepción tanto del idealismo como del materialismo vulgar, de la realidad. Del idealismo supera la primacía del sujeto -de corte solipsista- y del materialismo vulgar que borra por completo la subjetividad. La apuesta de Freire parte del materialismo dialéctico, desarrollado por Marx, en el que en la lógica objeto-sujeto ninguno se superpone al otro y hay una interrelación entre ambos. Freire también se deja acompañar por las ideas latinoamericanas de diversidad y la igualdad social como referente para cualquier propuesta contextualizada en nuestro subcontinente, ello lo asume a partir del pensamiento latinoamericano de la liberación que se manifestaba en su época.

La recuperación, revisión, reinterpretación y contextualización del planteamiento de Marx en esos movimientos de liberación es evidente y no es azarosa; se debe a que los movimientos sociales de izquierda -para la coyuntura en la que escribe Freire- estaban colmados por la posición estalinista; el estalinismo llevaba a que el partido se subyugara y a que los revolucionarios usaran métodos propios de la clase dominante de corte oligárquico para llevar a cabo "el cambio revolucionario". La posición de los revolucionarios, en la mayoría de los casos, llevaba a un sustitucionalismo de las masas, sin diálogo con ellas, y con la preconcepción de que los obreros o campesinos no podían llegar por sí mismos a la liberación.

Por otra parte, el planteamiento de la pedagogía del oprimido es la respuesta a lo que Horkheimer (2003) llamaba teoría tradicional, concepción educativa que utiliza la clase oligárquica para quitarle toda proyección subjetiva a la educación y hacer del sujeto un simple receptor de conocimiento, un objeto y no un sujeto o un ser ajeno y alejado de su realidad y de sus propios problemas.

Las preocupaciones de Freire, en tanto a lo anterior, iban en dos sentidos; primero superar la concepción educativa de la burguesía $\mathrm{y}$, segundo, en superar los métodos revolucionarios que utilizaban la concepción bancaria de la educación -supuestamente- en función de la liberación del oprimido y que, pretendiendo lo contrario, no pasaban de adoctrinar o alienar a los sujetos educativos. 
El peso de la cotidianidad -la introyección del opresor en la conciencia- hacen que el oprimido se niegue a sí mismo, su búsqueda de ser; se trata de un fatalismo a instalar en el sujeto: la apelación a que las cosas están dadas y no hay nada que hacer para cambiarlas. Se ha introyectado en su conciencia la concepción dominante del mecanicismo, en la que lo que esta cambia por sí sola y la división opresores-oprimidos no puede ser cambiada, o bien se trata de un destino natural que hay que aceptar.

El oprimido tiene en sí una dualidad en su ser; en primera instancia se trata de aquel que construye el mundo, pero no lo tiene en sus manos, $\mathrm{y}$ en un segundo momento este se encuentra mediado por el opresor, quien utiliza la educación para hacer o construir sujetos pasivos por medio de la repetición sin más.

La concepción pedagógica dominante -en esta dialéctica- se basa en la educación "bancaria"; en esta educación se privilegia la narración de hechos y no así la criticidad ni la producción creativa de propuestas o alternativas a los problemas que le aquejan a los sujetos educativos. Esa memorización estática, hace del concepto algo muerto, y borra de esta la viveza de enunciar un mundo concreto o contextualizado; la palabra pierde su razón de ser para convertirse en mera forma, que petrifica el mundo y hace de este algo cerrado, borrando la capacidad de transformación del sujeto sobre la materialidad. Así, el sujeto, entonces según Freire (1970), es visto como un recipiente vacío que hay que llenar.

Para la clase oligárquica, la educación es una herramienta por medio de la cual se sostiene su mundo, es por este medio que hace creer que sus necesidades objetivas son las necesidades de toda la especie humana (Fromm, 1970); por ello, implanta la idea de que el opresor es necesario para la existencia e introyecta conceptos de este en el oprimido, para que desee emular al opresor, pero no así transformar el mundo. $\mathrm{Al}$ respecto, Freire reitera que la pedagogía bancaria dominante vende la idea de que el oprimido está fuera del mundo, y es más bien obstáculo para sí mismo y para una "sociedad sana", por lo tanto, la solución es insertarles en esta sociedad, es su adaptación, que dejen de ser marginados (Freire, 1970). Al imponerse lo anterior, el oprimido ve su solución fuera de él y no en él mismo como sujeto transformador.

Esa idea la había desarrollado Marx cuando sostiene que los trabajadores, día con día en la relación objetiva con el mundo, mediante el producto de su trabajo, fetichizan el producto de sus manos y esto 
hace que el oprimido no se reconozca en lo que hace, textualmente este autor manifiesta: "el carácter misterioso de la forma mercancía estriba, por tanto, pura y simplemente, en que proyecta ante los hombres el carácter social del trabajo de estos como si fuese un carácter material de los propios productos de su trabajo, un don social de estos objetos" (Marx, 2007, p. 36).

La educación tradicional o bancaria se basa en el principio positivista de que todo tiene que ser cuantificado, racionalizado, descrito o planificado y en que además la subjetividad debe jugar un papel de mera expectación, dedicándose a acoger a la "objetividad" sin ningún prejuicio. He aquí la base sobre la cual se asienta la anulación del sujeto.

Para esta noción, el mundo se mueve como una totalidad mecánica, donde cualquier contradicción es simplemente una anomalía dentro del sistema, y, por lo tanto, la subjetividad no entra en la dinámica de cambio, a pesar de que la propia realidad y su estratificación social, generación de la desigualdad social y de género, de división de clases, la diversidad cultural, muestre claras contradicciones, y, sea, por demás, un producto social y no "natural".

Para profundizar más en los yacimientos de la educación bancaria, como planteaba la escuela de Frankfurt (Adorno y Horkheimer, 2006), sin contradicción no hay conocimiento, sin conflicto no hay historia; es en el reconocimiento de las contradicciones que se hace posible la imaginación y la creación, ya que de lo contrario todo estaría ya hecho y no habría nada por conocer.

Derivado de lo hasta aquí dicho, la educación bancaria asegura la enajenación del ser humano haciendo que este "no se sienta a sí mismo como portador activo de sus propias capacidades y riquezas, sino como una 'cosa' empobrecida que depende de poderes externos a él y en los que ha proyectado su sustancia vital" (Fromm, 1967, p. 29). En palabras de Freire, se plantea que el oprimido no se reconoce a sí mismo como oprimido, y esto hace que no vea la realidad tal cual es, y al tratar de transformarla termine delegando a otros -en este caso al opresor- la dirección de su vida (Freire, 1970).

En la relación del educando y educador -desde esa perspectiva tradicional- se profundiza la verticalidad, ya que al controlar y negar las capacidades del sujeto cognoscente se producirá una relación alienante, en la que el educador toma la actitud del opresor y el educando cede todo su potencial al educador. No hay una interacción dialógica entre 
ambos, sino todo lo contrario: una clara relación de poder que el educador no quiere perder, ya que se perdería a sí mismo como único portador del conocimiento. Freire rescata aquí la dialéctica hegeliana del amo y esclavo donde el esclavo -a pesar de ser el que conoce el mundo- ve este mundo mediado por su amo, y se pierde a sí mismo, dándose así la conciencia para el otro y no la conciencia para sí, reconociéndose en esta relación.

La sociedad burguesa, como cualquier sociedad humana está fundada en mitos, aunque su soberbia eurocéntrica lo niegue. Destacan como mitos fundadores de la misma, el de la propiedad privada, la igualdad de derechos, la "democracia" y la supuesta libertad -que no va más allá de la compra y venta-, la armonía entre las clases y la integración cultural; estos mitos, como ya se apuntó, son introyectados en el oprimido (educando) por medio de la educación bancaria y conllevan a idealizar al opresor.

Esa educación opresora al masificar y pretender alienar a los sujetos educativos promueve la incapacidad de plantear salidas u opciones a los oprimidos de su situación inferior, racializada y descolonizados; el ser humano, en su totalidad, bajo esta concepción, pretende ser depurado de su humanidad, perdiendo lo que lo diferencia de las demás especies animales: su capacidad de trabajo, de construir sus propios medios de vida, estancando así la evolución de la especie y atentando contra la vida misma.

Por ello, debido al carácter opresor de la educación bancaria, es que Freire apuesta por la pedagogía del oprimido; no solo criticará a los opresores sino a todos aquellos que utilizan, consciente o inconscientemente, el método de esta educación, para supuestamente así liberar a la especie humana. Es decir, en nombre de la liberación también se suelen reproducir métodos opresivos que se develan en el currículo oculto mediante prácticas docentes que están muy alejadas de la crítica, la producción de alternativas, la creatividad, la valoración positiva de la diversidad y la generación de valores consecuentes con una sociedad justa en la que quepamos todos/as, pero en la que no haya lugar para la discriminación y la desigualdad social. Por eso la producción de alternativas debe pasar por la autoconciencia del sujeto educativo -en situación de opresión-; según Freire, el oprimido debe ser partícipe de su liberación, o, aún mejor, sin tal proceso no es posible la liberación, por lo que problematizar su realidad es fundamental para construir una 
conciencia crítica de su situación y para buscar salidas concretas: se trata de aceptar, en primera instancia, que se está oprimido; es decir, no solo bastará con mejorar la economía y la redistribución de la riqueza -como lo creía el estalinismo-, sino que, y sobre todo, el ser humano tiene que darse cuenta de su condición de alienado, para evitar la reproducción de los vicios burgueses, con la finalidad de dejar de lado a su opresor interno o a su policía de la conciencia.

Para lograr esa autoconcientización de mi situación de colonizado, Freire saca de su propuesta al academicismo y apuesta por una pedagogía de base o popular, para y por los movimientos sociales y las comunidades campesinas, urbano marginalizadas, impulsando una pedagogía desde y con el oprimido (Freire, 1970) y no para el oprimido. Solo él se puede liberar a sí mismo, pero en relación comunitaria, donde el docente se convierte en un sujeto fundamental como mediador de la liberación colectiva, dado que nadie educa a nadie, sino que todos nos educamos juntos mediados por el mundo (Freire, 1970).

Los educadores como mediadores, en la obra Pedagogía del oprimido, encuentran como primera obligación propiciar un proceso de alfabetización crítica, para que el obrero, el campesino, la mujer, los/las niños/as o las y los estudiantes en general, encuentren su propia palabra para que no sean repetidores del conocimiento tradicional, y -como segundo "imperativo"-, está el planteamiento de la problematización como método para buscar salidas concretas a la realidad mediante la praxis revolucionaria.

En la educación liberadora, la relación educador-educando debe ser una relación horizontal, una relación de amor, en la que el conocimiento no se paralice ni sea estático y donde las relaciones de poder deben difuminarse sin desautorizar el saber de ninguno de los sujetos educativos. Por ejemplo, si ponemos el caso de un partido revolucionario, el educador tiene que reconocerse también a sí mismo en la dinámica opresor-oprimido, en tanto esté en diálogo con los suyos y apueste por la concientización de todos los sectores populares, para que por sí mismos se organicen y busquen su liberación, sin prácticas mesiánicas ni sustitucionalistas.

Freire plantea que la pedagogía del oprimido tiene la función de desenmascarar ideológicamente a la clase dominante, pero esto no será posible, como se ha dicho, si los oprimidos no experimentan en su sentir la opresión. Marcar todo hecho con el sello del sentimiento real 
del oprimido; se trata aquí de una revalorización de la experiencia, de darles voz a los y las que, por lo general, no tienen. Recapitulando, sin la conciencia de ser oprimido es imposible la acción transformadora.

Aquí cabe aclarar una diferencia: reconocerse como oprimido y ser consciente de estar en tal condición son situaciones distintas; por una parte, el reconocimiento per se no lleva a la práctica liberadora pues no supera el plano de lo objetivo. "Reconocerse" -en antagonismo al opresor- en aquella forma, no significa estar en lucha por la superación de la contradicción. Podría presentarse, entonces, la situación de que uno de los polos de la contradicción (el oprimido) pretenda, en vez de la liberación, la identificación con su contrario (el opresor) (Freire, 1970). Ser consciente, por su parte, expresa una dimensión subjetiva que puede llevar al oprimido a tomar parte activa en su reconocimiento.

El elemento fundamental de una educación liberadora será la dialogicidad; el diálogo se convertirá en un requisito ontológico de esta educación, ya que por medio de este se previene que alguno de los partícipes de la relación que se viene planteando dialécticamente (opresor-oprimido) pretenda verticalizar el conocimiento. El diálogo entendido en términos de necesidad existencial, como el encuentro de seres humanos que se pronuncian sobre sobre sus realidades, en sus dimensiones fundamentales (estética, epistemológica, política, ética), procura el bienestar social de todos y todas (Freire, 1970). La vereda del diálogo será el único camino -al modo de una utopía- para la construcción de las condiciones materiales para la emancipación (Hinkelammert, 1984). Así, el diálogo, en contraposición al materialismo objetivista, sería una garantía para evitar la reproducción de relaciones de opresión.

\section{¿Cómo generar este diálogo del que nos habla Freire?}

El rescate de valores humanos -como la humildad y el amor- se vuelve imprescindible; humildad para no legar la ignorancia solo al otro, sino para tener la posibilidad -y la virtud- de reconocerse en ella; amor en su sentido fraterno: ver en el otro el carácter de lo humano -de humanidad-, el mismo que hay en mí, que me define como un ser sentipensante (Galeano, 2010).

Tanto la humildad como el amor se nos presentan como componentes, requisitos -elementos definitorios y posibilitadores- del diálogo, de no ser así este pierde su razón de ser; sino seremos víctimas, 
por ejemplo, como señala Rancière (2003), de los monólogos -de las explicaciones y de los explicadores-, de los atontamientos, y de un entorpecimiento del proceso de aprendizaje: de una verticalización $a$ priori del saber.

\section{A modo de conclusión}

La pedagogía del oprimido de Paulo Freire constituye una herramienta fundamental para desmitificar el mundo en el que vivimos, en el que la clase dominante -a causa de la misma crisis sistémica que la vio nacer- sobreideologiza los hechos para perpetuarse en el poder.

Ante la ultra especialización de la educación liberadora se nos presenta como fundamental preguntar por lo humano -por el desarrollo integral de lo propiamente humano-, se trata de una salida para hacerle frente a la teoría tradicional educativa, en la que se espera un producto, en el que más que seres humanos se esperan autómatas (que no piensen ni sientan), para legitimar la sobreexplotación en la vida diaria.

Solo rescatando la imaginación y la creatividad -propia y ajenaes posible vislumbrar un mundo nuevo, e ir por su transformación; de lo contrario será imposible superar aquella conjetura ingenua de que el capitalismo y la configuración social, que legitima a la burguesía, caerán por sí solos. Solamente un sujeto consciente de su condición -y de sus necesidades- es capaz de convertirse en portavoz del cambio. Esta idea de sujeto debe entenderse en términos de un sujeto social, colectivo.

Establecer las condiciones dialógicas en la relación educador-educando, en fomento de la horizontalidad, encuentra un ser que aprende motivado no por lo que pueda repetir sino por la posibilidad de transformarse y de transformar la situación del colectivo. Por otra parte, la dialogicidad hace posible, en el caso del educador, el reconocerse humanos, eliminar la mística de lo educativo: dejar de pensar y pensarse como el sabio cerrado -y encerrado- que se hace acreedor, en sí mismo, del conocimiento y de la configuración del mundo.

Una educación que no tenga por eje la creación de "sujetos" competitivos, configurada a sí misma bajo el imperio de una meritrocracia -como medida de quién sabe "más" o "menos"-, podrá ver el conocimiento como aquella posibilidad de investigar conjuntamente y de forma constante en la inagotable transformación de la realidad. 
El planteamiento de Freire trasciende la academia y lo académico, su aporte va más allá: se trata de un llamado a las organizaciones que se pretenden revolucionarias, a que se alejen de las concepciones fundamentalistas como lo era el estalinismo de partido y sus formas análogas presentes en la educación.

Las organizaciones comunales, partidarias, institucionales o no -en el plano educativo- encuentran, después de Freire, la obligación de dialogar, y con ello el imperativo de propiciar para las condiciones del diálogo: estar con las masas y no situarse por encima de ellas. Lo que exige, a su vez, un diálogo desde la diversidad y la horizontalidad como se ha apuntado a lo largo de este escrito.

La desalienación es fundamental en el planteamiento freireano, consiste en la apuesta por ese sujeto que reconozca su historia y sea capaz -colectivamente- de tomar por sí mismo las riendas del mundo, sin tener que apelar a entes externos a su conciencia de humano, como los dioses, o el capital. En síntesis, el ejercicio que se plantea es el de no negar las contradicciones, el de reconocer el principio fundamental de la transformación de la materia e ir por su humanización.

La pedagogía del oprimido es una propuesta para conocer la condición humana actual, así como plantea Morin, conocer que somos resultado del cosmos, de la naturaleza, de la vida, pero debido a nuestra humanidad misma, a nuestra cultura, a nuestra mente, a nuestra conciencia; nos hemos vuelto extraños a este cosmos que nos es secretamente íntimo. Nuestro pensamiento y nuestra conciencia, los cuales nos hacen conocer este mundo físico, nos alejan otro tanto. (Morin, 1999, p. 25)

O como lo dicen los pueblos indígenas de nuestro subcontinente, nada está separado de nada, todo está relacionado entre sí, es la historia como fenómeno cíclico la que nos lleva a dar sentido a la realidad que ya es compleja por sí misma.

\section{Referencias}

Adorno, T. y Horkheimer, M. (2006). Dialéctica de la ilustración. España: Trotta.

Freire, P. (1970). Pedagogía del oprimido. México: FCE.

Fromm, E. (1967). Psicoanálisis de la sociedad contemporánea. México: FCE.

Fromm, E. (1970). La condición humana actual. Argentina: Siglo XXI. 
Fromm, E. (1984). Sobre la desobediencia y otros ensayos. Argentina: Paidós.

Galeano, E. (2010). El libro de los abrazos. México: Siglo XXI

Hinkelammert, F. (1984). Crítica a la razón utópica. Costa Rica: DEI.

Horkheimer, M. (2003). Teoría crítica. Argentina: Amorrortu.

Marx, K. (2007). El capital. México: FCE.

Morin, E. (1999). Los siete saberes necesarios para la educación del futuro. Francia: UNESCO

Rancière, J. (2003). El maestro ignorante. España: Laertes. 